\title{
Influence of Structural Defects on the Properties of Metamagnetic Shape Memory Alloys
}

\author{
J. I. Pérez-Landazábal ${ }^{1,2, * \mathbb{C}}$, V. Sánchez-Alarcos ${ }^{1,2}$, V. Recarte ${ }^{1,2}{ }^{(\mathbb{D}}$, O. A. Lambri ${ }^{3}$, \\ F. G. Bonifacich ${ }^{3}$, D. L.R. Khanna ${ }^{1,2}$, I. Unzueta ${ }^{4}$ (), J.A. García ${ }^{5,6}$, F. Plazaola ${ }^{7}$,
} J. López-García ${ }^{1,8}$, M. Jimenez Ruiz ${ }^{8}$, J.A. Rodríguez-Velamazán ${ }^{8}$ (i) and E. Cesari ${ }^{9}$ (1)

1 Departamento de Ciencias, Public University of Navarra (UPNa), 31006 Pamplona, Spain; vicente.sanchez@unavarra.es (V.S.-A.); recarte@unavarra.es (V.R.); deepali.khanna@unavarra.es (D.L.R.K.); javier.lopezg@unavarra.es (J.L.-G.)

2 Institute for Advanced Materials and Mathematics INAMAT ${ }^{2}$, Universidad Pública de Navarra, 31006 Pamplona, Spain

3 Laboratorio de Materiales, Escuela de Ingeniería Eléctrica, Centro de Tecnología e Investigación Eléctrica, Facultad de Ciencias Exactas, Ingeniería y Agrimensura, Universidad Nacional de Rosario-CONICET, Avda. Pellegrini 250, 2000 Rosario, Argentina; olambri@fceia.unr.edu.ar (O.A.L.); bonifaci@fceia.unr.edu.ar (F.G.B.)

4 Matematika Aplikatua Saila, Bilboko Ingenieritza Eskola, Euskal Herriko Unibersitatea UPV/EHU, p.k. 644, 48080 Bilbao, Spain; iraultza.unzueta@ehu.eus

5 Fisika Aplikatua II Saila, Euskal Herriko Unibersitatea UPV/EHU, p.k. 644, 48080 Bilbao, Spain; joseangel.garcia@ehu.es

6 BC Materials (Basque Centre for Materials, Applications and Nanostructures), 48080 Leioa, Spain

7 Elektrizitate eta Elektronika Saila, Euskal Herriko Unibersitatea UPV/EHU, p.k. 644, 48080 Bilbao, Spain; fernando.plazaola@ehu.es

8 Institut Laue Langevin, 71, Avenue des Martyrs, 38042 Grenoble CEDEX, France; jimenez@ill.fr (M.J.R.); velamazan@ill.eu (J.A.R.-V.)

9 Departament de Física, Universitat de les Illes Balears, Ctra. de Valldemossa, km 7.5, E-07122 Palma de Mallorca, Spain; eduard.cesari@uib.cat

* Correspondence: ipzlanda@unavarra.es; Tel.: +34-948168448

Received: 17 July 2020; Accepted: 20 August 2020; Published: 22 August 2020

\begin{abstract}
The production of $\mu$-particles of Metamagnetic Shape Memory Alloys by crushing and subsequent ball milling process has been analyzed. The high energy involved in the milling process induces large internal stresses and high density of defects with a strong influence on the martensitic transformation; the interphase creation and its movement during the martensitic transformation produces frictional contributions to the entropy change (exothermic process) both during forward and reverse transformation. The frictional contribution increases with the milling time as a consequence of the interaction between defects and interphases. The influence of the frictional terms on the magnetocaloric effect has been evidenced. Besides, the presence of antiphase boundaries linked to superdislocations helps to understand the spin-glass behavior at low temperatures in martensite. Finally, the particles in the deformed state were introduced in a photosensitive polymer. The mechanical damping associated to the Martensitic Transformation (MT) of the particles is clearly distinguished in the produced composite, which could be interesting for the development of magnetically-tunable mechanical dampers.
\end{abstract}

Keywords: metamagnetic shape memory alloys; structural defects; magnetocaloric effect; mechanical damping 


\section{Introduction}

The change in the interatomic distances caused by the occurrence of a thermoelastic Martensitic Transformation (MT) in Metamagnetic Shape Memory Alloys (MSMA) results in large magnetization changes $(\Delta M)$ at the transformation temperature [1-4]. In fact, the strong dependence of the magnetic exchange interactions on the Mn-Mn distances [5-7] is responsible for such a change and allows the induction of the MT by external magnetic fields. The large magnetoresistance or the giant inverse magnetocaloric properties are among others, relevant effects for sensing and magnetic refrigeration [8-14] that make these alloys interesting from the application point of view. Besides, the inherent damping properties of shape memory alloys can be used for active noise reduction and mechanical damping applications $[15,16]$. The damping in the case of MSMA, can be controlled by an external magnetic field through the hysteretic induced MT. In particular, Ni-Mn-In and Ni-Mn-Sn show a MT between a ferromagnetic austenite and a weak-magnetic martensite. The compositional [17-20] and atomic order [21-24] influence on the MT properties has been widely studied in the literature. Although the long-range atomic order in Ni-Mn-In alloys can be easily controlled by means of thermal treatments, the Ni-Mn-Sn system shows a highly stable L2 1 structure where the atomic order can hardly be modified by conventional thermal treatments. The addition of Cobalt in both cases enhances the ferromagnetic ordering of the austenite and reduces the magnetism in martensite in Ni-Mn-X alloys, thus leading to an increase of $\Delta \mathrm{M}$ and therefore to larger magnetically-induced shifts of the MT temperature [1,25-28].

On the other side, the new Additive Manufacturing (AM) technology (3D printing) opens a huge field in devices design, for example using polymers with different percentages of functional particles. In this context, the metallic particle production, their characterization and properties optimization are milestones to get valuable functional composites [29-33]. Mechanical milling is a simple method to produce micro and nanoparticles but unfortunately produces huge internal stress, defects and deformations that strongly modifies properties of the bulk alloy [34-39]. As an example, the high density of the anti-phase boundaries linked to dislocations produced during the milling process [40] or the local atomic disordering in boundary region [29] promotes antiferromagnetic coupling between Mn moments and consequently a reduction in the saturation magnetization of both martensitic and austenitic phases.

In this work, a hand crushing and subsequent ball milling process has been tested to produce $\mathrm{Ni}_{45} \mathrm{Co}_{5} \mathrm{Mn}_{37} \mathrm{In}_{13} \mu$-particles to be introduced in a photosensitive polymer. The high energy involved in the process produces large internal stresses and high density of defects with a strong influence on the MT. The work is focused on the analysis of the influence of milling on the structural and magnetic properties of MSMA. The frictional contribution to the MT entropy change has been shown to increase with the milling time. Besides, the presence of antiphase boundaries linked to superdislocations helps to understand a spin-glass behavior found at low temperatures. A prospective study for future applications has been analyzed; in particular, the refrigeration capacity of the $\mu$-particles and the damping properties of the designed composites has been tested.

\section{Materials and Methods}

$\mathrm{Ni}_{45} \mathrm{Co}_{5} \mathrm{Mn}_{36} \mathrm{In}_{14}$ Metamagnetic alloys were synthetized from high purity elements by arc-melting under protective argon atmosphere. The bulks obtained were homogenized at $1170 \mathrm{~K}$ during $24 \mathrm{~h}$. The composition of the alloys was analyzed by EDS in a JSM-5610LV Scanning Electron Microscope (SEM, Jeol, Tokio, Japan). The alloys were milled in an agate mortar until reaching a uniform particle-size distribution. Subsequently, a systematic ball milling was performed at Room Temperature (RT) and at different milling times (15, 30, 45, 60, $90 \mathrm{~min}$ ) in a Retsch PM4 under argon atmosphere and controlled temperature, avoiding the possibility of oxidation. As-crushed powders were used to produce the MSMA $\mu$ Particle-Polymers composites. The polymeric matrix was a commercial photo curable bisphenol A-glycidyl methacrylate (Bis-GMA) resin (Schmidt Composite flow Madrid, Spain). The MT was characterized by differential scanning calorimetry (Q-100 Differential Scanning Calorimeter, 
DSC, TA Instruments, New Castle, DE, USA) at a heating/cooling rate of $10 \mathrm{~K} / \mathrm{min}$. The macroscopic magnetic characterization of the alloys was performed by SQUID magnetometry (QD MPMS XL-7, Quantum Design, San Diego, CA, USA) under different fields from 100 Oe to $60 \mathrm{kOe}$. High-Resolution X-rays Powder Diffraction (HRXPD,) was carried out in the BL04_MPSD beamline (28 keV) at ALBA synchrotron, Barcelona, Spain using a high-resolution detector $(\operatorname{mad} 26)[41,42]$. Diffraction data treatment was carried out using the programs of the Fullprof Suite [43]. Dynamic Mechanical Analysis (DMA) measurements, loss tangent (damping), $\tan (\phi)$, and dynamic shear modulus, $\mathrm{G}^{\prime}$, were carried out as a function of temperature in a homemade torsion pendulum at frequencies close to $5 \mathrm{~Hz}$. Measurements were performed during heating and cooling with a rate of $1 \mathrm{~K} / \mathrm{min}$. Measurements were performed under Argon atmosphere at atmospheric pressure.

\section{Results and Discussion}

Figure 1 shows the DSC thermograms performed on cooling/heating in the bulk, hand-crushed and ball-milled samples. The occurrence of a first-order MT is evidenced by the presence of the hysteretic exothermic (forward MT) and endothermic (reverse MT) peaks at around $275 \mathrm{~K}$ and $295 \mathrm{~K}$ respectively. A second-order magnetic transition taking place in the austenitic phase can be inferred from the $\lambda$-type shoulder linked to the Curie temperature observed around $T_{c}=388 \mathrm{~K}$. Focusing on the MT peak, the area below the peak clearly decreases with deformation. Nevertheless, the peak position does not change, indicating that the long-range atomic order does not evolve with deformation, in agreement with the inalterability of the Curie temperature. Figure 1 right shows the evolution of the enthalpy change at the MT with the milling time. A clear decrease is observed for the hand-crushed sample, and then a gradual decrease of the enthalpy takes place as the milling time increases (after $60 \mathrm{~min}$ the MT practically disappears). The easiest way to understand this behavior is assuming a reduction in the transforming volume fraction as a consequence of the induced internal stresses (defects, deformations) during hand crushing or milling processes. Nevertheless, deformation itself can also contribute to the transformation enthalpies and entropies.
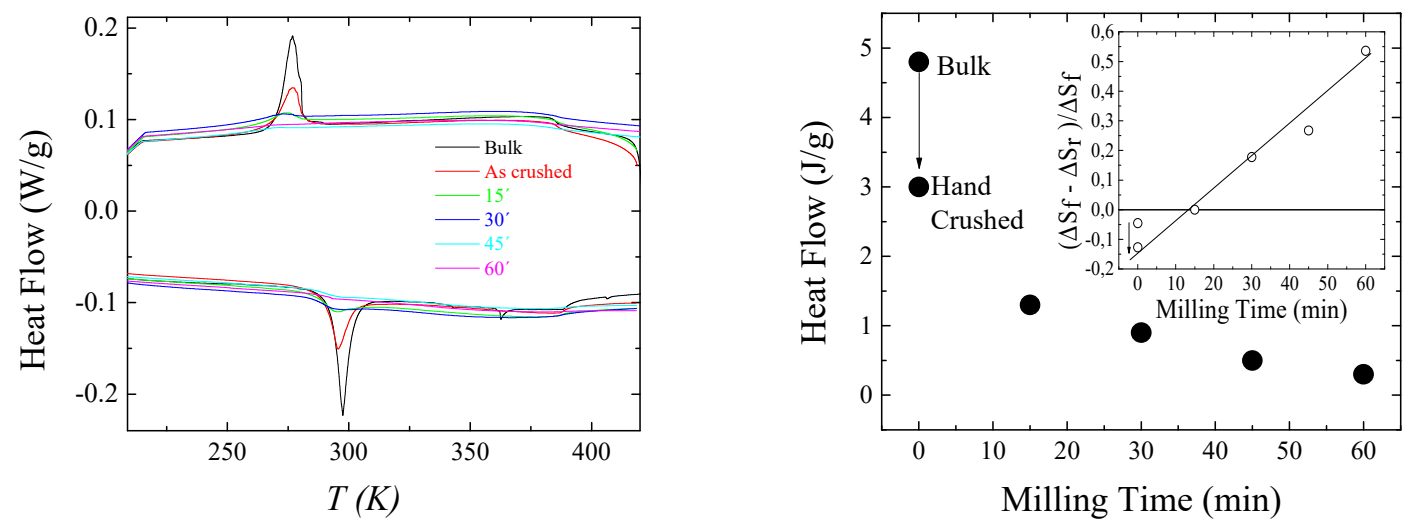

Figure 1. DSC measurements around the MT for bulk, as-crushed, and milled sample (left). The evolution of the heat flow (forward MT) as a function of the milling time is shown on the right side (the inset shows the normalized difference between forward and reverse entropies).

The entropy change linked to the MT, which limits the magnetocaloric effect, can be considered as the sum of a vibrational, $\Delta S_{\mathrm{vib}}$, and a magnetic, $\Delta S_{\mathrm{mag}}$, terms (the small electronic term is usually

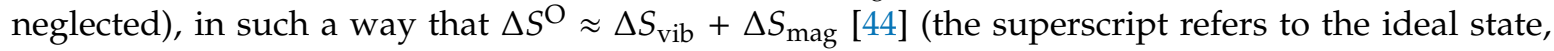
where the frictional contribution to entropy is negligible). For the martensite to austenite transformation (reverse transformation) in metamagnetic shape memory alloys, the vibrational and the magnetic terms are positive and negative, respectively, the vibrational one being necessarily higher [44]. The opposite occurs in the forward MT being the vibration entropy change negative and positive the magnetic contribution. The MT occurs around the Debye temperature $\left(\theta_{\mathrm{D}}=310 \pm 25 \mathrm{~K}\right.$ for austenite in a similar 
but ordered alloy [45]), and then a nearly constant vibrational contribution in a first approximation can be assume in both forward and reverse MT. Since $\Delta S_{\text {mag }}$ is directly related to $\Delta M$, a higher magnetic contribution opposing the vibrational one should be expected in the forward (lower temperature) than in the reverse transformation (closer to the Curie temperature), which would lead to a lower net $\Delta S^{\mathrm{O}}$ in the forward MT than in the reverse $\Delta S^{\mathrm{O}}{ }_{\mathrm{r}}$. So, the difference (in absolute values) between forward and reverse entropies should be always negative. The inset in Figure 1 right shows the evolution of this difference (normalized to the forward entropy change to avoid volume transforming effects) and only for short milling times the difference is negative. In fact the difference turns into positive for milling times longer than $15 \mathrm{~min}$. The large contribution of the magnetic entropy and its temperature dependence makes this system not easy to analyze. In particular, to analyze the effect of defects on the entropy change the previous contributions should be well stablished. $\Delta S$ typically increases because of the microstructural recovery brought by annealing, as in fact occurs in ternary Ni-Mn-Sn alloys [46]). This indicates that defects tend to reduce the entropy change linked to the MT. Nevertheless, the influence of defects (point defects, dislocations, and anti-phase boundaries) in the MT thermodynamics should be different in the direct and reverse transformation. The interphase creation and its movement during the MT produces frictional contributions to the entropy change $\left(\Delta S_{\mathrm{F}}\right)$ both during forward and reverse transformation. In both cases, the entropy change term is negative (exothermic process). So, taking into account this contribution, the entropy change can be written as: $\Delta S_{\mathrm{f}}(-) \approx \Delta S_{\mathrm{f}}^{\mathrm{O}}(-)+\Delta S_{\mathrm{F}, \mathrm{f}}(-)$ for the direct and $\Delta S_{\mathrm{r}}(+) \approx \Delta S_{\mathrm{r}}^{\mathrm{O}}(+)+\Delta S_{\mathrm{F}, \mathrm{r}}(-)$ for the reverse. As a consequence, the absolute value $\Delta S_{\mathrm{f}}$ increases and $\Delta S_{\mathrm{r}}$ decreases. So, long milling times makes the difference $\left(\Delta S_{\mathrm{f}}-\Delta S_{\mathrm{r}}\right)$ positive in absolute values (see inset in Figure 1 right). Therefore, defects influence on the entropy change through the frictional terms and then modifies the magnetocaloric capacities and all the other properties linked to the thermodynamics of the MT.

The crystallographic analysis performed after different milling times allow to determine the phase distribution at high ( $350 \mathrm{~K}$ ) and low (245 K) temperatures (see Figure 2). The bulk alloy at high temperature shows an austenitic structure (not shown here) but after hand crushing, the induced stresses prompt a small partial transformation to martensite. The subsequent ball milling process induces the presence of much higher martensite fractions at high temperatures (see Figure 2, left). This effect is well known and is usually linked to stress-induced martensitic transformations [47-49]. Besides, an increasing fraction of amorphous phase seems to be present as deformation increase. On heating, the transformation to austenite occurs but the required temperature depends on the stabilization degree. In the present case, the diffraction spectra were measured at $350 \mathrm{~K}$ after heating the sample to $420 \mathrm{~K}$ indicating that some martensite is still stabilized at $420 \mathrm{~K}$. On the other side, at low temperatures, the presence of higher martensite fractions shows that the MT is taking place. The evolution of the austenite reflections (see reflections at $2 \theta=7.4^{\circ}$ or $21.2^{\circ}$ i.e.,) shows that some austenite is retained at low temperatures because of deformation. Nevertheless, the higher is the deformation (longer milling times) the lower is the quantity of out-of-equilibrium austenite at low temperatures (the fraction of austenite at $250 \mathrm{~K}$ change from $15 \%$ in the As-crushed and 30 'milled samples sample to $8 \%$ in the sample milled during $60^{\prime}$ ). Moreover, there exists an increasing amorphous contribution (broad peaks superimposed to the main reflections) with the milling times. 

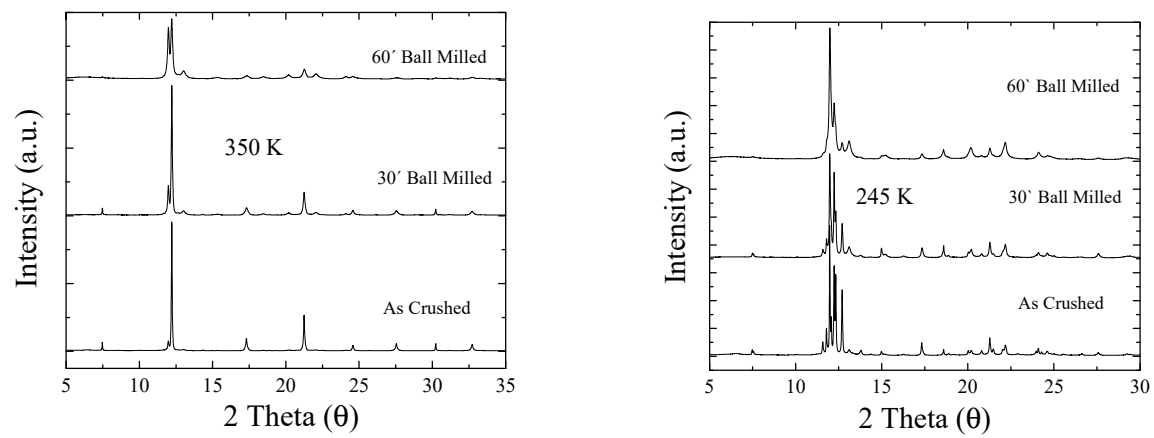

Figure 2. Powder X-ray diffraction patterns at $350 \mathrm{~K}$ (left) and $245 \mathrm{~K}$ (right) for the as-crushed and 30 'and 60'milled samples. The measurements were performed after cooling from $420 \mathrm{~K}$.

The gradual widening of the reflection peaks with the milling time evidences the expected decrease of the grain size and increase of internal strains. Figure 3 shows the evolution of both parameters estimated from Lebail fit of the $420 \mathrm{~K}$ diffractograms obtained for milling times up to $60^{\prime}$. For longer times, the MT practically disappears. So, deformation induces internal stresses that promotes the martensite formation. The percentage of sample undergoing the MT highly decreases with the milling time since the induced martensite does not transform on cooling. This agrees with the reduction of the enthalpy change at MT with the milling time (see Figure 1 right).

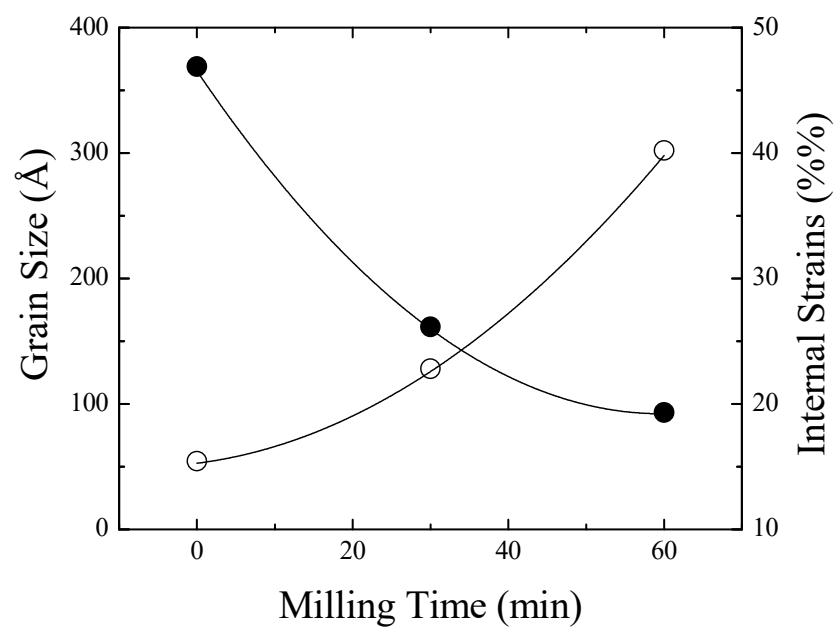

Figure 3. Evolution of the diffracting size (black holes) and internal strains (white holes) measured at $420 \mathrm{~K}$ as a function of the milling time.

Magnetic measurements have been carried out on the as-crushed and milled samples to compare the microstructure with the magnetic behavior. Figure 4 shows the temperature dependence of the magnetization at high $(60 \mathrm{kOe})$ and low $(100 \mathrm{Oe})$ magnetic fields. The ferromagnetic austenite transforms to a superparamagnetic-like martensite, showing the characteristic thermal hysteresis. Obviously, the induction of superparamagnetic-like martensite during milling reduces the high field magnetization above the MT. For the longer milling time, the MT is hardly detectable. So, the jump in high-field magnetization at the MT decreases with the milling time, as expected from the gradual increase of the stress-induced martensite. On the other side, the magnetization jump at low magnetic fields linked to the Curie temperature occurs at around $400 \mathrm{~K}$ except in the sample milled more than $60 \mathrm{~min}$. In all cases, the MT temperature shows always approximately the same shift to lower temperatures upon the application of high magnetic fields. Besides, both the Curie temperature and the MT temperature remain almost constant irrespectively of the milling time, which again would indicate the absence of variations on the long-range atomic order. As shown in Figure 4 (left), there exists a much stronger influence of the mechanically-induced defects on the magnetization in austenite 
than in martensite. Apart from the magnetic nature of each phase, local atomic order variations at antiphase boundaries (APB) produced between superdislocations as a consequence of the mechanical deformations could be also playing a role [39].
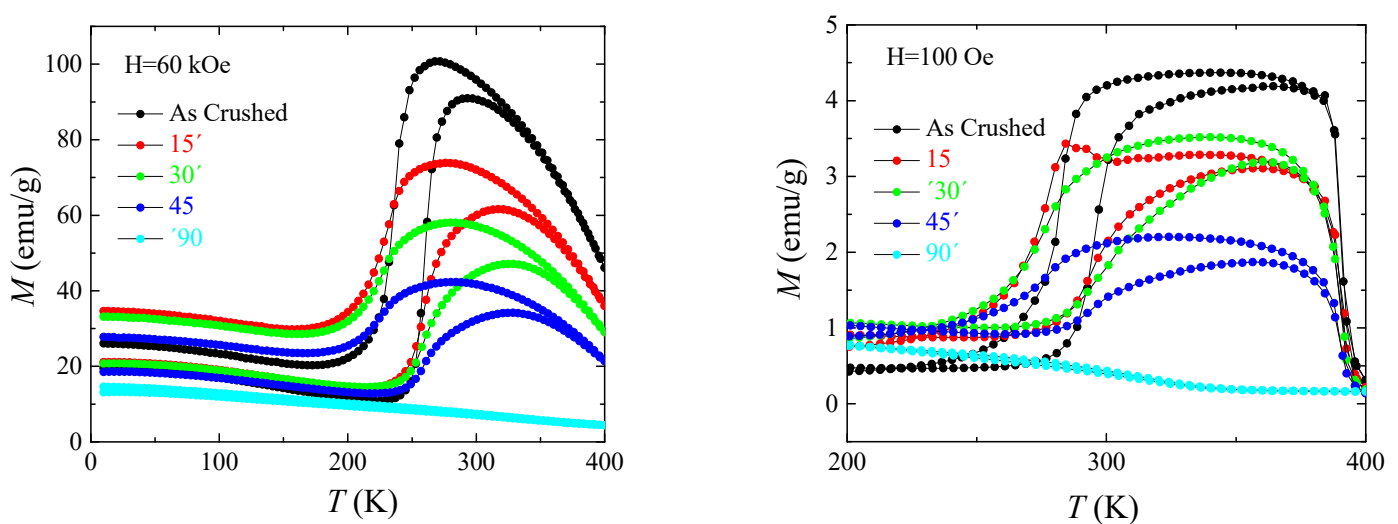

Figure 4. Temperature dependence of the magnetization at high, $60 \mathrm{kOe}$ (left) and low, $100 \mathrm{Oe}$ (right) magnetic fields.

The magnetic field dependence of the magnetization has been also measured at $10 \mathrm{~K}$ to better analyze the effect of milling in martensite. The obtained magnetization curves are shown in Figure 5 (left). For milling times below $30 \mathrm{~min}$, the magnetization curves are similar whereas for longer milling times the magnetization decreases. This result agree with the evolution of the austenite at low temperature; the fraction of ferromagnetic austenite changes from 15\% in the as-crushed and 30'milled samples to $8 \%$ in the sample milled during 60'. The high magnetization values (20 emu/g) observed in the samples milled during short milling-times is a consequence of the high retained fraction of austenite. Besides, the presence of increasing amounts of amorphous phase with apparently very low magnetization and the reduction in the content of austenite for longer milling times reduces the magnetization of the alloy.
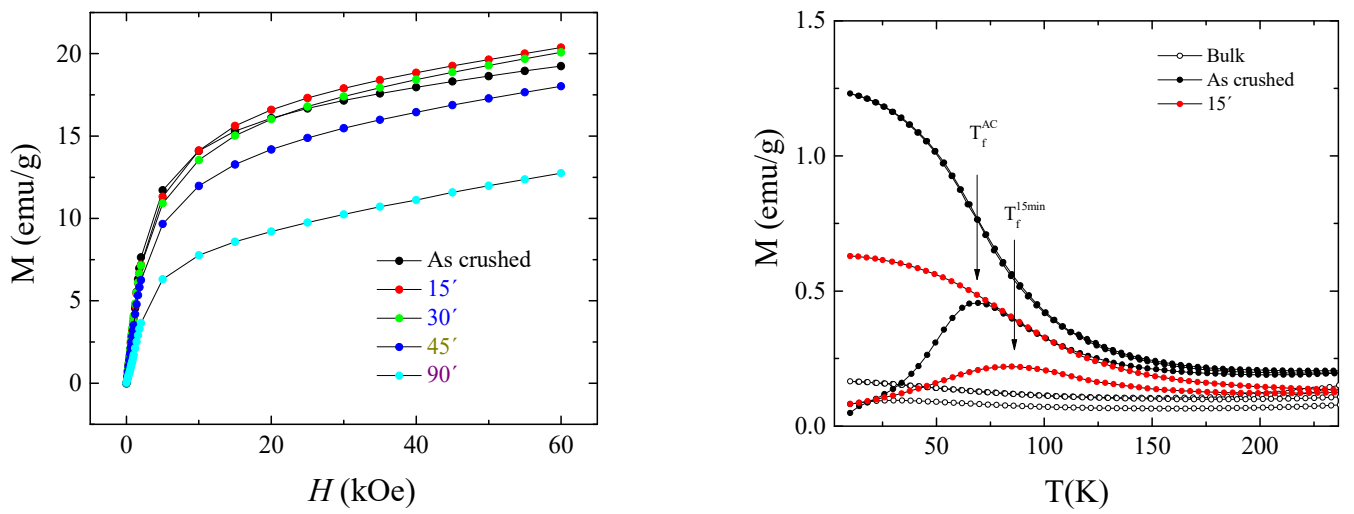

Figure 5. Left: Magnetization $M(H)$ curves at $10 \mathrm{~K}$ after a Zero Field Cooled procedure (ZFC). Right: ZFC-Field Cooled (FC) measurement under low magnetic field (100 Oe).

Figure 5 right shows the magnetization versus temperature at 100 Oe without deformation (bulk) and with deformation (as-crushed and 15' ball milling). The thermomagnetic curves were measured by two processes; cooled to $10 \mathrm{~K}$ in zero field and then measured on heating (ZFC curve), and measurement on subsequent cooling (FC curve). The difference between both curves at low temperatures in both deformed samples shows the thermomagnetic history effect typical of the spin-glass behaviour [50]. The maximum in the curves corresponds to the freezing temperature, $\mathrm{T}_{\mathrm{f}}$ [50]. The bulk sample does not show the presence of such a maximum. Deformation makes the magnetization (the magnetic susceptibility) increase but the milled sample shows lower susceptibility than the as-crushed sample. 
The low magnetic moment of the martensite (see Figure 4 left) must be associated to the coexistence of ferromagnetic and antiferromagnetic interactions. Different mechanisms, i.e., reentrant spin glasses, superparamagnetism, superspin glasses or antiferromagnetism have been proposed to explain their superparamagnetic-like behavior [50-52]. In particular, the presence of local changes in the interatomic distance has been shown to promote changes in the magnetic interaction. This occurs in the Antiphase Boundaries (APB) region between superdislocations in ordered alloys [51]. So, a deformation dependence of the low field magnetization could be expected. APB's can be considered as regions of enhanced ferromagnetic interaction that increase the overall susceptibility of the phase. The presence of smaller grains and higher strains in the milled sample (see Figure 3) can reduce the overall susceptibility with respect to the as-crushed alloy. Nevertheless, this point requires a more exhaustive analysis. On the other side, the freezing temperature increases slightly with increasing strain (see Figure 5). The shift of the freezing temperature to higher temperature as a consequence of the amount of defects has been observed in other materials [53]. Before deformation, the paramagnetic state does not show any spin-glass like behavior. Indeed, the deformed samples have two magnetic states above $\mathrm{T}_{\mathrm{f}}$, ferromagnetic clusters locate along the APB and paramagnetic-like state surrounding the APB. These paramagnetic and ferromagnetic states change to the spin-glass at $\mathrm{T}_{\mathrm{f}}$ in the deformed samples. The results indicate that the freezing temperature $T_{f}$ depends on the deformation degree, increasing with the quantity of dislocations [51].

Although other approaches have been proposed in the literature based on the temperature derivative of the Helmoltz-free energy [54,55], the MCE, defined as the field induced entropy change $\Delta S_{\text {iso }}$ in isothermal conditions, has been calculated according to classical thermodynamics through the temperature dependence of magnetization (curves not shown here but similar to those shown in Figure 4 but at different applied magnetic fields). The measured $\Delta S_{\text {iso }}$ for a powder milled during 15' as a function of temperature and magnetic field is shown in Figure 6.

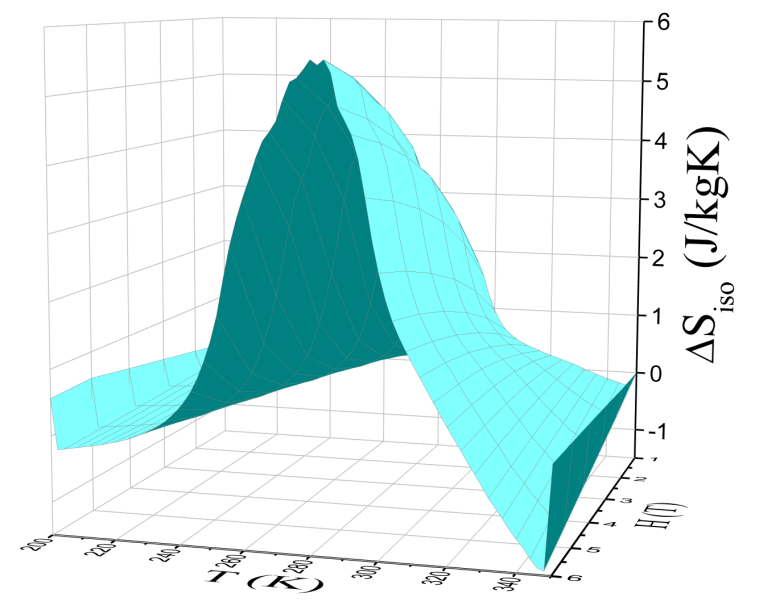

Figure 6. Temperature and field dependence of the magnetic field induced entropy change $(\Delta S)$ in a $15^{\prime}$ ball milled sample.

A positive peak (inverse MCE) is observed linked to the magnetostructural transformation at the MT. The MCE values increase with the increasing magnetic field, reaching a maximum value of around $\Delta S_{\text {iso }} \approx 5 \mathrm{~J} / \mathrm{kgK}$ at $60 \mathrm{kOe}$. The $\Delta S_{\text {iso }}$ comes from the magnetic induction of the MT which is limited by the maximum entropy change found in Figure 2 for the sample milled during $15^{\prime}(\Delta S \approx 5 \mathrm{~J} / \mathrm{kgK})$. The results seem to indicate that a field of $60 \mathrm{kOe}$ is high enough to induce the full available MT. Although the measured value is small comparing with the bulk entropy change, a subsequent high temperature thermal treatment should remove the defects and improve their MCE properties. Further work is in progress to improve their MCE capabilities.

From the application point of view, the production of MSMA $\mu$-particles opens the possibility of producing MSMA-particle containing polymers (composites) by different techniques and in particular 
by Additive Manufacturing (AM) technology (3D printing). The new AM technology opens a huge field, for example, in the design of heat exchangers for magnetic refrigeration grounded on the inverse magnetocaloric effect or in the design of tunable (using for example external magnetic fields) damping devices. To check the potential capacities in both fields, preliminary studies have been performed on the particles, concerning the magnetic field induced entropy change and the damping properties.

For this last application, the hand crushed powders were embedded in a photosensitive polymer. Figure 7 shows the temperature dependence of the damping $(\tan (\phi))$ and dynamic shear modulus $\left(G^{\prime}\right)$ of the composite. The damping spectra show the peak related to the glass transition of the polymer, $\mathrm{Tg}$, at around $340 \mathrm{~K}$ and its related fall in the dynamic modulus at around $300 \mathrm{~K}$, overlapped to the MT. Nevertheless, composites show a well-defined damping peak at around $285 \mathrm{~K}$ (labelled as MT), overlapped on the low temperature side of the glass transition peak. There exists a clear change in the shear modulus linked to the damping peak. Both the peak and the modulus defect show a temperature hysteresis related to the MT. So, the damping of the polymer reflects the effect of the MT and consequently the application of external magnetic fields could change for example the transformation temperature and consequently the temperature range where the damping is maximum. Obviously, much more efforts are necessary to understand and design tunable dampers using this technology but these previous results seem to be promising.

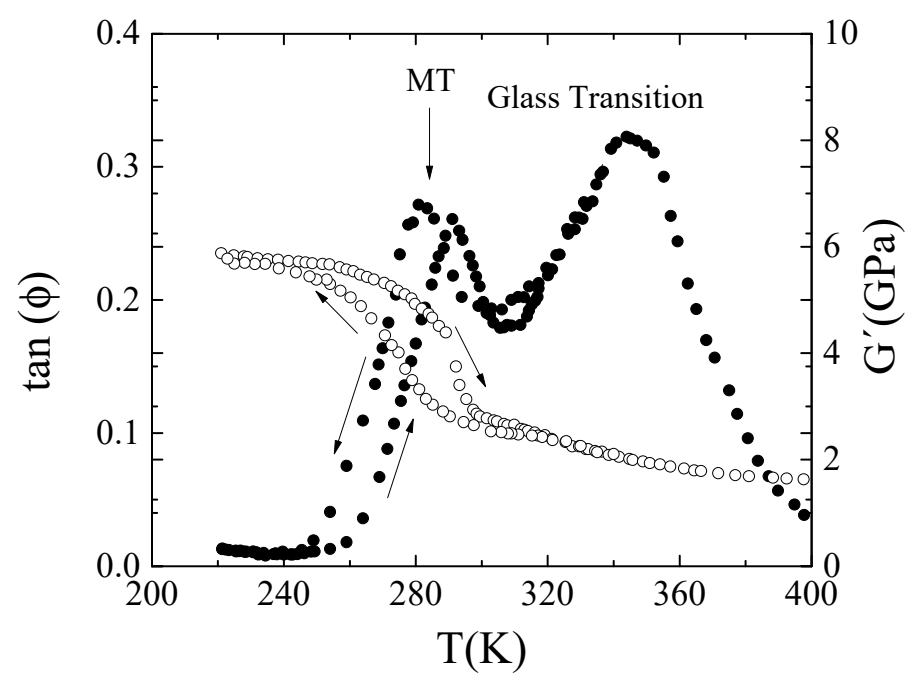

Figure 7. Damping $\left(\tan (\phi)\right.$, black holes) and shear modulus ( $\mathrm{G}^{\prime}$, white holes) as function of temperature measured in a Metamagnetic Shape Memory Alloy-Polymer composite.

\section{Conclusions}

A crushing and subsequent ball milling process has been tested to produce MSMA $\mu$-particles. The particles in the deformed state were introduced in a photosensitive polymer to check their damping capacity. The high energy involved in the milling process produces large internal stresses and high density of defects with a strong influence on the MT characteristics. Deformations induce internal stresses that promotes the MT; the interphase creation and its movement during the MT produces frictional contributions to the entropy change (exothermic process) both during forward and reverse transformation modifying the absolute values of the total entropy. The frictional contribution increases with the milling time as a consequence of the interaction between defects and interphases. The influence of the frictional terms on the MCE has been evidenced. Besides, the presence of antiphase boundaries linked to superdislocations helps to understand the spin-glass behavior at low temperatures in martensite. Finally, the damping of the produced composites reflects the MT, so the elaborated composites appear to be promising candidates to the development of mechanical dampers tuned by external magnetic fields. 
Author Contributions: Conceptualization, J.I.P.-L., V.S.-A. and V.R.; methodology, J.I.P.-L., V.S.-A. and V.R.; formal analysis J.I.P.-L., O.A.L., J.A.G. and F.P.; investigation, I.U., J.L.-G., M.J.R., J.A.R.-V. and E.C.; writing-original draft preparation, J.I.P.-L.; writing—review and editing, J.I.P.-L., V.S.-A., V.R., O.A.L., F.G.B., D.L.R.K., I.U., J.A.G., F.P., J.L.-G., M.J.R., J.A.R.-V. and E.C.; supervision, J.I.P.-L.; All authors have read and agreed to the published version of the manuscript.

Funding: This research was funded by Projects RTI2018-094683-B-C5 (4,5) (MCIU/AEI/FEDER,UE); ASACTEI Pcia.Santa Fe IO-2017-00138, PID-UNR ING 575 and ING 612 (2018-2021).

Acknowledgments: D.L.R.K. wants to acknowledge UPNA and InaMat ${ }^{2}$ for the Ph.D. Grant (Ayudas para contratos pre-doctorales adscritas a grupos e instittutos de investigación UPNA) We acknowledge ALBA Synchrotron for the beam time allocations: BL04_MPSD beamline with the collaboration of ALBA staff (Proposal ref. 2018022796). Authors also want to thank the Cooperation Agreement between the Universidad Pública de Navarra and the Universidad Nacional de Rosario, Res. CS. 3247/2015. 2015-2020 and the Cooperation Agreement between the Universidad del País Vasco and the Universidad Nacional de Rosario, Res. C. S. 3243 del 30/12/2015. 2015-2020.

Conflicts of Interest: The authors declare no conflict of interest.

\section{References}

1. Kainuma, R.; Imano, Y.; Ito, W.; Sutou, Y.; Morito, H.; Okamoto, S.; Kitakami, O.; Oikawa, K.; Fujita, A.; Kanomata, T.; et al. Magnetic-field-induced shape recovery by reverse phase transformation. Nature 2006, 439, 957-960. [CrossRef] [PubMed]

2. Koyama, K.; Watanabe, K.; Kanomata, T.; Kainuma, R.; Oikawa, K.; Ishida, K. Observation of field-induced reverse transformation in ferromagnetic shape memory alloy Ni50Mn36Sn14. Appl. Phys. Lett. 2006, 88,132505 . [CrossRef]

3. Oikawa, K.; Ito, W.; Imano, Y.; Sutou, Y.; Kainuma, R.; Ishida, K.; Okamoto, S.; Kitakami, O.; Kanomata, T. Effect of magnetic field on martensitic transition of Ni46Mn41In13 Heusler alloy. Appl. Phys. Lett. 2006, 88, 122507. [CrossRef]

4. Acet, M.; Mañosa, L.; Planes, A. Chapter Four-Magnetic-Field-Induced Effects in Martensitic Heusler-Based Magnetic Shape Memory Alloys; Buschow, K.H.J., Ed.; Elsevier: Amsterdam, The Netherlands, 2011; Volume 19.

5. Şaşığlu, E.; Sandratskii, L.M.; Bruno, P. First-principles calculation of the intersublattice exchange interactions and Curie temperatures of the full Heusler alloys Ni2MnX (X=Ga, In, Sn). Phys. Rev. B 2004, 70, 24427. [CrossRef]

6. Şaşığlu, E.; Sandratskii, L.M.; Bruno, P. Role of conduction electrons in mediating exchange interactions in Mn-based Heusler alloys. Phys. Rev. B 2008, 77, 64417. [CrossRef]

7. Buchelnikov, V.D.; Entel, P.; Taskaev, S.V.; Sokolovskiy, V.V.; Hucht, A.; Ogura, M.; Akai, H.; Gruner, M.E.; Nayak, S.K. Monte Carlo study of the influence of antiferromagnetic exchange interactions on the phase transitions of ferromagnetic Ni-Mn-X alloys (X=In, Sn, Sb). Phys. Rev. B 2008, 78, 184427. [CrossRef]

8. Kainuma, R.; Ito, W.; Umetsu, R.Y.; Khovaylo, V.V.; Kanomata, T. Metamagnetic shape memory effect and magnetic properties of Ni-Mn based Heusler alloys. Mater. Sci. Forum 2011, 684, 139-150. [CrossRef]

9. Yu, S.Y.; Liu, Z.H.; Liu, G.D.; Chen, J.L.; Cao, Z.X.; Wu, G.H.; Zhang, B.; Zhang, X.X. Large magnetoresistance in single-crystalline Ni50Mn50-xInx alloys $(x=14-16)$ upon martensitic transformation. Appl. Phys. Lett. 2006, 89, 162503. [CrossRef]

10. Sharma, V.K.; Chattopadhyay, M.K.; Shaeb, K.H.B.; Chouhan, A.; Roy, S.B. Large magnetoresistance in Ni50Mn34In16 alloy. Appl. Phys. Lett. 2006, 89, 222509. [CrossRef]

11. Krenke, T.; Duman, E.; Acet, M.; Wassermann, E.F.; Moya, X.; Mañosa, L.; Planes, A. Inverse magnetocaloric effect in ferromagnetic Ni-Mn-Sn alloys. Nat. Mater. 2005, 4, 450-454. [CrossRef]

12. Krenke, T.; Duman, E.; Acet, M.; Wassermann, E.F.; Moya, X.; Mañosa, L.; Planes, A.; Suard, E.; Ouladdiaf, B. Magnetic superelasticity and inverse magnetocaloric effect in Ni-Mn-In. Phys. Rev. B 2007, 75, 104414. [CrossRef]

13. Planes, A.; Mañosa, L.; Acet, M. Magnetocaloric effect and its relation to shape-memory properties in ferromagnetic Heusler alloys. J. Phys. Condens. Matter 2009, 21, 233201. [CrossRef] [PubMed]

14. Liu, J.; Gottschall, T.; Skokov, K.P.; Moore, J.D.; Gutfleisch, O. Giant magnetocaloric effect driven by structural transitions. Nat. Mater. 2012, 11, 620-626. [CrossRef] [PubMed] 
15. Pérez-Landazábal, J.I.; Lambri, O.A.; Bonifacich, F.G.; Sánchez-Alarcos, V.; Recarte, V.; Tarditti, F. Influence of defects on the irreversible phase transition in Fe-Pd ferromagnetic shape memory alloys. Acta Mater. 2015, 86, 110-117. [CrossRef]

16. Bonifacich, F.G.; Lambri, O.A.; Pérez-Landazábal, J.I.; Gargicevich, D.; Recarte, V.; Sánchez-Alarcos, V. Mobility of Twin Boundaries in Fe-Pd-Based Ferromagnetic Shape Memory Alloys. Mater. Trans. 2016, 57, 1837-1844. [CrossRef]

17. Sutou, Y.; Imano, Y.; Koeda, N.; Omori, T.; Kainuma, R.; Ishida, K.; Oikawa, K. Magnetic and martensitic transformations of $\mathrm{NiMnX}(\mathrm{X}=\mathrm{In}, \mathrm{Sn}, \mathrm{Sb})$ ferromagnetic shape memory alloys. Appl. Phys. Lett. 2004, 85, 4358-4360. [CrossRef]

18. Krenke, T.; Acet, M.; Wassermann, E.F.; Moya, X.; Mañosa, L.; Planes, A. Martensitic transitions and the nature of ferromagnetism in the austenitic and martensitic states of Ni-Mn-Sn alloys. Phys. Rev. B 2005, 72, 14412. [CrossRef]

19. Krenke, T.; Acet, M.; Wassermann, E.F.; Moya, X.; Mañosa, L.; Planes, A. Ferromagnetism in the austenitic and martensitic states of Ni-Mn-In alloys. Phys. Rev. B 2006, 73, 174413. [CrossRef]

20. Khan, M.; Dubenko, I.; Stadler, S.; Ali, N. Magnetostructural phase transitions in Ni50Mn25+xSb25-xHeusler alloys. J. Phys. Condens. Matter 2008, 20, 235204. [CrossRef]

21. Recarte, V.; Pérez-Landazábal, J.I.; Sánchez-Alarcos, V.; Rodríguez-Velamazán, J.A. Dependence of the martensitic transformation and magnetic transition on the atomic order in Ni-Mn-In metamagnetic shape memory alloys. Acta Mater. 2012, 60, 1937-1945. [CrossRef]

22. Recarte, V.; Pérez-Landazábal, J.I.; Sánchez-Alarcos, V. Dependence of the relative stability between austenite and martensite phases on the atomic order in a Ni-Mn-In Metamagnetic Shape Memory Alloy. J. Alloys Compd. 2012, 536, S308-S311. [CrossRef]

23. Sánchez-Alarcos, V.; Recarte, V.; Pérez-Landazábal, J.; Cesari, E.; Rodríguez-Velamazán, J. Long-Range Atomic Order and Entropy Change at the Martensitic Transformation in a Ni-Mn-In-Co Metamagnetic Shape Memory Alloy. Entropy 2014, 16, 2756-2767. [CrossRef]

24. Sánchez-Alarcos, V.; Pérez-Landazábal, J.I.; Recarte, V.; Lucia, I.; Vélez, J.; Rodríguez-Velamazán, J.A. Effect of high-temperature quenching on the magnetostructural transformations and the long-range atomic order of $\mathrm{Ni}-\mathrm{Mn}-\mathrm{Sn}$ and Ni-Mn-Sb metamagnetic shape memory alloys. Acta Mater. 2013, 61, 4676-4682. [CrossRef]

25. Kainuma, R.; Imano, Y.; Ito, W.; Morito, H.; Sutou, Y.; Oikawa, K.; Fujita, A.; Ishida, K.; Okamoto, S.; Kitakami, O.; et al. Metamagnetic shape memory effect in a Heusler-type Ni43Co7Mn39Sn11 polycrystalline alloy. Appl. Phys. Lett. 2006, 88, 192513. [CrossRef]

26. Nayak, A.K.; Suresh, K.G.; Nigam, A.K. Giant inverse magnetocaloric effect near room temperature in Co substituted NiMnSb Heusler alloys. J. Phys. D. Appl. Phys. 2009, 42, 35009. [CrossRef]

27. Huang, L.; Cong, D.; Suo, H.; Wang, Y. Giant magnetic refrigeration capacity near room temperature in Ni40Co10Mn40Sn10 multifunctional alloy. Appl. Phys. Lett. 2014, 104, 132407. [CrossRef]

28. Umetsu, R.Y.; Sheikh, A.; Ito, W.; Ouladdiaf, B.; Ziebeck, K.R.A.; Kanomata, T.; Kainuma, R. The effect of Co substitution on the magnetic properties of the Heusler alloy Ni50Mn33Sn17. Appl. Phys. Lett. 2011, 98, 42507. [CrossRef]

29. Lahelin, M.; Aaltio, I.; Heczko, O.; Söderberg, O.; Ge, Y.; Löfgren, B.; Hannula, S.-P.; Seppälä, J. DMA testing of Ni-Mn-Ga/polymer composites. Compos. Part A Appl. Sci. Manuf. 2009, 40, 125-129. [CrossRef]

30. Scheerbaum, N.; Hinz, D.; Gutfleisch, O.; Müller, K.-H.; Schultz, L. Textured polymer bonded composites with Ni-Mn-Ga magnetic shape memory particles. Acta Mater. 2007, 55, 2707-2713. [CrossRef]

31. Feuchtwanger, J.; Richard, M.L.; Tang, Y.J.; Berkowitz, A.E.; O’Handley, R.C.; Allen, S.M. Large energy absorption in Ni-Mn-Ga/polymer composites. J. Appl. Phys. 2005, 97, 10M319. [CrossRef]

32. Liu, J.; Scheerbaum, N.; Kauffmann-Weiss, S.; Gutfleisch, O. NiMn-Based Alloys and Composites for Magnetically Controlled Dampers and Actuators. Adv. Eng. Mater. 2012, 14, 653-667. [CrossRef]

33. Tian, B.; Chen, F.; Tong, Y.; Li, L.; Zheng, Y. Magnetic field induced strain and damping behavior of Ni-Mn-Ga particles/epoxy resin composite. J. Alloys Compd. 2014, 604, 137-141. [CrossRef]

34. Alves, A.L.; Passamani, E.C.; Nascimento, V.P.; Takeuchi, A.Y.; Larica, C. Influence of grain refinement and induced crystal defects on the magnetic properties of Ni50Mn36Sn14Heusler alloy. J. Phys. D Appl. Phys. 2010, 43, 345001. [CrossRef] 
35. Passamani, E.; Nascimento, V.; Larica, C.; Takeuchi, A.; Alves, A.; Capua Proveti, J.; Pereira, M.; Fabris, J. The influence of chemical disorder enhancement on the martensitic transformation of the Ni 50Mn 36Sn 14 Heusler-type alloy. J. Alloy. Compd. 2011, 509, 7826-7832. [CrossRef]

36. Ghotbi Varzaneh, A.; Kameli, P.; Zahedi, V.R.; Karimzadeh, F.; Salamati, H. Effect of heat treatment on martensitic transformation of Ni47Mn40Sn13 ferromagnetic shape memory alloy prepared by mechanical alloying. Met. Mater. Int. 2015, 21, 758-764. [CrossRef]

37. Czaja, P.; Przewoźnik, J.; Fitta, M.; Bałanda, M.; Chrobak, A.; Kania, B.; Zackiewicz, P.; Wójcik, A.; Szlezynger, M.; Maziarz, W. Effect of ball milling and thermal treatment on exchange bias and magnetocaloric properties of Ni48Mn39.5Sn10.5Al2 ribbons. J. Magn. Magn. Mater. 2016, 401, 223-230. [CrossRef]

38. Wang, X.; Sun, F.; Wang, J.; Yu, Q.; Wu, Y.; Hua, H.; Jiang, C. Influence of annealing temperatures on the magnetostructural transition and magnetocaloric effect of Ni40Co10Mn40Sn10 powders. J. Alloys Compd. 2017, 691, 215-219. [CrossRef]

39. Unzueta, I.; López-García, J.; Sánchez-Alarcos, V.; Recarte, V.; Pérez-Landazábal, J.I.; Rodríguez-Velamazán, J.A.; Garitaonandia, J.S.; García, J.A.; Plazaola, F. 119Sn Mössbauer spectroscopy for assessing the local stress and defect state towards the tuning of Ni-Mn-Sn alloys. Appl. Phys. Lett. 2017, 110, 181908. [CrossRef]

40. Murakami, Y.; Yanagisawa, K.; Niitsu, K.; Park, H.S.; Matsuda, T.; Kainuma, R.; Shindo, D.; Tonomura, A. Determination of magnetic flux density at the nanometer-scale antiphase boundary in Heusler alloy Ni50Mn25Al12.5Ga12.5. Acta Mater. 2013, 61, 2095-2101. [CrossRef]

41. Fauth, F.; Peral, I.; Popescu, C.; Knapp, M. The new Material Science Powder Diffraction beamline at ALBA Synchrotron. Powder Diffr. 2013, 28, S360-S370. [CrossRef]

42. Peral, I.; McKinlay, J.; Knapp, M.; Ferrer, S. Design and construction of multicrystal analyser detectors using Rowland circles: Application to MAD26 at ALBA. J. Synchrotron Radiat. 2011, 18, 842-850. [CrossRef] [PubMed]

43. Rodríguez-Carvajal, J. Recent advances in magnetic structure determination by neutron powder diffraction. Phys. B Condens. Matter 1993, 192, 55-69. [CrossRef]

44. Recarte, V.; Pérez-Landazábal, J.I.; Sánchez-Alarcos, V.; Zablotskii, V.; Cesari, E.; Kustov, S. Entropy change linked to the martensitic transformation in metamagnetic shape memory alloys. Acta Mater. 2012, 60, 3168-3175. [CrossRef]

45. Pérez-Landazábal, J.I.; Recarte, V.; Sánchez-Alarcos, V.; Ruiz, M.J.; Cesari, E. Outstanding role of the magnetic entropy in arrested austenite in an ordered Ni45Mn36.7In13.3Co5 metamagnetic shape memory alloy. Scr. Mater. 2019, 168, 91-95. [CrossRef]

46. López-García, J.; Unzueta, I.; Sánchez-Alarcos, V.; Recarte, V.; Pérez-Landazábal, J.I.; Rodríguez-Velamazán, J.A.; García, J.A.; Plazaola, F. Correlation between defects and magneto-structural properties in Ni-Mn-Sn metamagnetic shape memory alloys. Intermetallics 2018, 94, 133-137. [CrossRef]

47. Li, G.T.; Liu, Z.H.; Ma, X.Q.; Yu, S.Y.; Liu, Y. Grinding-induced martensite stabilization in Mn50Ni33.5Sn8Co8.5 alloy. Mater. Lett. 2013, 107, 239-242. [CrossRef]

48. Singh, S.; Kushwaha, P.; Scheibel, F.; Liermann, H.-P.; Barman, S.R.; Acet, M.; Felser, C.; Pandey, D. Residual stress induced stabilization of martensite phase and its effect on the magnetostructural transition in $\mathrm{Mn}$-rich Ni-Mn-In/Ga magnetic shape-memory alloys. Phys. Rev. B 2015, 92, 20105. [CrossRef]

49. Chulist, R.; Czaja, P.; Tokarski, T.; Faryna, M. Martensite stabilisation in single crystalline Ni-Mn-Ga and Ni-Mn-Sn magnetic shape memory alloys. Mater. Lett. 2018, 230, 266-269. [CrossRef]

50. Umetsu, R.Y.; Fujita, A.; Ito, W.; Kanomata, T.; Kainuma, R. Determination of the magnetic ground state in the martensite phase of $\mathrm{Ni}-\mathrm{Mn}-\mathrm{Z}(\mathrm{Z}=\mathrm{In}, \mathrm{Sn}$ and $\mathrm{Sb})$ off-stoichiometric Heusler alloys by nonlinear AC susceptibility. J. Phys. Condens. Matter 2011, 23, 326001. [CrossRef]

51. Larumbe, S.; Unzueta, I.; Sánchez-Alarcos, V.; Pérez-Landazábal, J.I.; Recarte, V.; García, J.A.; Plazaola, F. Low temperature magnetic properties of a Ni50Mn34In16 ball-milled metamagnetic shape memory alloy. J. Non. Cryst. Solids 2016, 447, 16-20. [CrossRef]

52. Sánchez-Alarcos, V.; Recarte, V.; Pérez-Landazábal, J.I.; Larumbe, S.; Caballero-Flores, R.; Unzueta, I.; García, J.A.; Plazaola, F.; Rodríguez-Velamazán, J.A. Mechanically induced disorder and crystallization process in Ni-Mn-In ball-milled alloys. J. Alloys Compd. 2016, 689, 983-991. [CrossRef]

53. Takahashi, S.; Chiba, A.; Takahashi, E. The influence of plastic deformation on the spin-glass in Fe-37.0 at.\% Al compound. Phys. Lett. A 1995, 197, 350-352. [CrossRef] 
54. L'vov, V.A.; Kosogor, A.; Barandiaran, J.M.; Chernenko, V.A. Theoretical description of magnetocaloric effect in the shape memory alloy exhibiting metamagnetic behavior. J. Appl. Phys. 2016, 119, 13902. [CrossRef]

55. Kosogor, A.; L'vov, V.; Lázpita, P.; Seguí, C.; Cesari, E. Magnetocaloric Effect Caused by Paramagnetic Austenite-Ferromagnetic Martensite Phase Transformation. Metals 2018, 9, 11. [CrossRef]

(C) 2020 by the authors. Licensee MDPI, Basel, Switzerland. This article is an open access article distributed under the terms and conditions of the Creative Commons Attribution (CC BY) license (http://creativecommons.org/licenses/by/4.0/). 